J. Lake Sci. (湖泊科学), 2012, 24(3): 422-428

http: //www. jlakes.org. E-mail : jlakes@niglas.ac.cn

(C) 2012 by Journal of Lake Sciences

\title{
南京玄武湖浮游甲壳动物的水平分布及其与环境的关系*
}

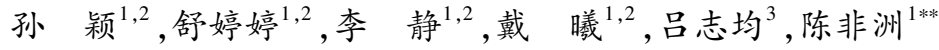 \\ (1: 中国科学院南京地理与湖泊研究所湖泊与环境国家重点实验室,南京 210008) \\ (2: 中国科学院研究生院, 北京 100049 ) \\ (3:河海大学水利水电学院,南京 210098$)$
}

摘 要: 于 2010 年 7 月对玄武湖三个区域 (荷花区、湖岸区、敞水区) 的浮游甲壳动物水平分布进行了分析, 并探讨了浮 游甲壳动物种类、丰度分布与环境因子的关系. 结果显示: 荷花区、湖岸区、敞水区的氮磷营养盐浓度无显著差异,三个区 域 $\mathrm{pH}$ 逐渐变高. 相比其他区域, 荷花区叶绿素 $\mathrm{a}$ 浓度最高而总悬浮质浓度最低. 荷花区浮游甲壳动物丰度显著高于敞水 区和湖岸区. 全湖枝角类优势种为模糊秀体溞、微型裸腹溞、尖额溞以及壳纹船卵溞. 桡足类的优势种为北碚中剑水蚤和 台湾温剑水蚤. 与其他湖区相比, 荷花区浮游甲壳动物种类最多, 且检出缺刺新秀体溞等稀有枝角类. 几余分析 (RDA) 表 明与玄武湖浮游甲壳动物优势种分布相关的重要环境因子为总悬浮质、叶绿素 $\mathrm{a}$ 和总溶解磷浓度. 结合浮游甲壳动物种 类、丰度分布及环境因子分析得出, 模糊秀体掻更倾向于分布在敞水区, 而荷花区为其余大部分浮游甲壳动物种类提供 了合适的生存条件.

关键词: 浮游甲壳动物;水平分布;挺水植物; 缺刺新秀体溞;玄武湖

\section{Horizontal distribution characteristics of crustacean planktons and its relationship with en- vironmental factors in Lake Xuanwu, Nanjing City}

\author{
SUN Ying ${ }^{1,2}$, SHU Tingting ${ }^{1,2}$, LI Jing ${ }^{1,2}$, DAI Xi ${ }^{1,2}$, LÜ Zhijun ${ }^{3} \&$ CHEN Feizhou ${ }^{1}$ \\ (1: State Key Laboratory of Lake Science and Environment, Nanjing Institute of Geography and Limnology, Chinese Academy \\ of Sciences, Nanjing 210008, P. R. China) \\ (2: Graduate University of Chinese Academy of Sciences, Beijing 100049, P. R. China) \\ (3: College of Water Conservancy and Hydropower, Hohai University, Nanjing 210098, P. R. China)
}

\begin{abstract}
A comparative study on the horizontal distribution of crustacean planktons was carried out in three different areas (water lily vegetation area, littoral zone and pelagic zone) in Lake Xuanwu on July 31, 2010. The relationship between distributions of crustacean planktons and environmental factors was analyzed. The results showed that the abundance of crustacean planktons was significantly higher in the water lily vegetation area than in the littoral and pelagic zone. The dominant species of cladocera during the survey were Diaphanosoma dubium, Moina micrura, Alona sp. and Scapholeberis kingi. Mesocyclops pehpeiensis and Thermocyclops taihokuensis dominated the copepod community. Comparing to other areas, most species of crustacean planktons were occurred in the water lily vegetation area, such as a rare cladocera Neodiaphanosoma volzi. Redundancy analysis showed that the most important factors impacting on the horizontal distribution of crustacean planktons were concentrations of total suspended solids , chlorophyll-a and total dissolved phosphorus. Thus, aquatic macrophytes such as water lily vegetation might provide adequate refuge to crustacean planktons with poor swimming ability, and might be one important factor to determine the horizontal distribution of crustacean planktons in Lake Xuanwu.
\end{abstract}

Keywords: Crustacean plankton; horizontal distribution; emergent aquatic plant; Neodiaphanosoma volzi; Lake Xuanwu

* 国家自然科学基金项目(31170440)资助. 2011-07-15 收稿;2011-11-13 收修改稿. 孙颖,女, 1985 年生,硕士研 究生;E-mail:reackeysun@163. com.

** 通信作者;E-mail:feizhch@ niglas. ac. cn. 
浮游甲壳动物包括枝角类和桡足类, 是水生态系统的重要组成部分, 具有连接食物网、维持生态系统稳 定等重要作用. 浮游甲壳动物在浅水湖泊的水平分布主要受捕食压力、食物密度、水生植物庇护等生物因子 以及氮磷营养盐、 $\mathrm{pH}$ 、溶解氧及浊度等环境理化因子的影响. 捕食压力主要体现在鱼类、虾类及无脊椎动物 对其的摄食 ${ }^{[1-3]}$; 一般认为, 浮游甲壳动物喜好生活在食物密度高的水域 ${ }^{[4]}$, 然而也有研究发现在富营养湖 泊中, 浮游甲壳动物丰度与浮游植物丰度呈负相关 ${ }^{[5]}$; 高等水生植物可以成为浮游甲壳动物躲避鱼类捕食 的庇护所, 其中关于沉水植物和浮叶植物对浮游甲壳动物的庇护作用研究较多 ${ }^{[6-8]}$, 而有关挺水植物的庇护 效果却鲜有报道 ${ }^{[9]}$. 理化因子也会对浮游甲壳动物的水平分布产生显著的影响, 其中营养盐水平在一定范 围内越高, 浮游甲壳动物丰度也越高 ${ }^{[10]}$; 大部分浮游甲壳动物对 $\mathrm{pH}$ 要求并不严格, 但少数浮游甲壳动物却 需要环境有稳定的 $\mathrm{pH}$ 范围 ${ }^{[11-12]}$; 有研究表明浮游甲壳动物丰度与溶解氧呈正相关, 与浊度呈负相关, 但有 些枝角类 (如秀体泽) 并不受浊度的影响 ${ }^{[13]}$.

城市湖泊一般指城市中小型自然或人工水体, 具有生态、防洪、娱乐、旅游等功能. 目前关于城市湖泊浮 游甲壳动物的研究比较少, 国外有研究表明, 由于城市湖泊易被土地利用和人类污染等因素影响, 其浮游甲 壳动物丰度普遍少于同气候条件下的其他湖泊 ${ }^{[14]}$, 同时其种类也有小型化的趋势 ${ }^{[15]}$. 作为典型的亚热带城 市浅水湖泊, 武汉东湖的营养水平及滤食性鱼类的捕食压力是导致浮游甲壳动物群落在东湖不同湖区具有 不同分布格局的重要因素 ${ }^{[16]}$. 在热带城市湖泊中, 鱼类捕食也会降低浮游甲壳动物的丰度, 而有水生植物的 湖泊中其丰度则相对较高 ${ }^{[17]}$.

玄武湖位于南京市区, 是典型的亚热带城市浅水湖泊. 其水面面积约 $3.68 \mathrm{~km}^{2}$, 平均水深 $1.14 \mathrm{~m}$, 最大 水深 $2.31 \mathrm{~m}$. 全湖被 4 个小岛分割成北湖、东南湖和西南湖三部分, 彼此通过桥洞相连. $1980 \mathrm{~s}$ 末, 玄武湖水 质就已达到富营养程度, 其中浮游甲壳动物的种类、丰度以及优势种等方面在该时期已经有明显变化 ${ }^{[18]}$. 作 为城市景观湖, 玄武湖遍布大量观赏性植物荷花. 荷花为该湖夏季最主要的大型水生植物, 对浮游甲壳动物 有一定的庇护作用 ${ }^{[9]}$, 但是否会影响浮游甲壳动物在全湖中的分布还有待研究. 本研究在全湖设置 40 个采 样点, 通过对玄武湖不同湖区浮游甲壳动物的种类及丰度的调查, 分析不同生物和理化因子对其分布的 影响.

\section{1 材料与方法}

\section{1 采样点设置}

2010 年 7 月 31 日, 对南京玄武湖浮游甲壳动 物种类、丰度及相关环境因子进行调查, 依据玄武 湖形态及环境特点设置 40 个采样点, 其中荷花区 设有 13 个采样点, 湖岸区设有 16 个采样点 (距岸 $20 \mathrm{~m}$ 以内), 敞水区设有 11 个采样点 (图 1).

\section{2 采样与分析}

采样时用 YSI 6600 现场测定水温、pH 及溶解 氧 (DO). 用 $5 \mathrm{~L}$ 采水器在采样点表层及底层各取 水样一次, 充分混匀后取 $2.5 \mathrm{~L}$ 装人避光塑料瓶带 回实验室立即测定总氮 $(T N)$ 、总溶解氮 $(T D N)$ 、总 磷 (TP) 、总溶解磷 (TDP) 、总悬浮质 (TSS)、叶绿素 $a($ Chl. a) 等水质指标. TN 、 TP、TDN、TDP 用碱性过 硫酸钾消解法测定; Chl. a 测定方法为取水样

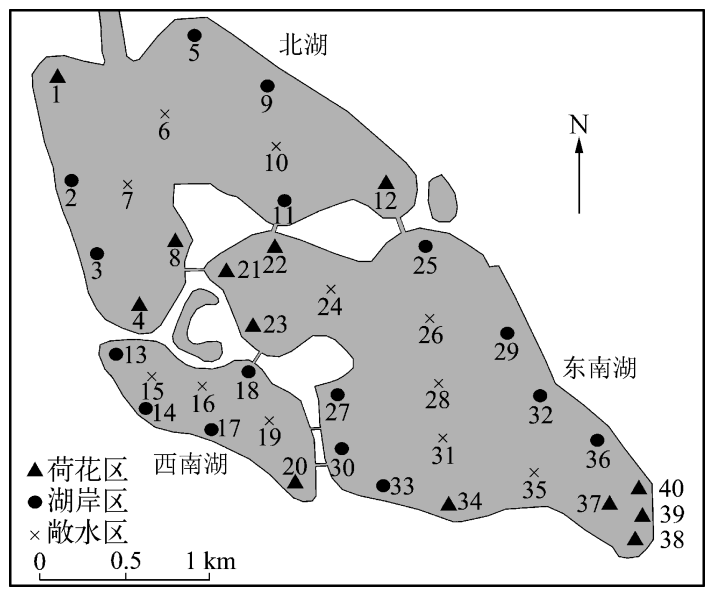

图 1 玄武湖采样点分布示意图

Fig. 1 Distribution of sampling sites in Lake Xuanwu $100 \mathrm{ml}$, 通过醋酸纤维膜 ( 孔径 $0.45 \mu \mathrm{m}$ ) 抽滤, 滤膜用 $90 \%$ 丙酮溶液 $4{ }^{\circ} \mathrm{C}$ 萃取 $24 \mathrm{~h}$, 取上清液用紫外分光光 度计测定并计算 ${ }^{[19]}$.

用 $5 \mathrm{~L}$ 采水器在采样点表层及底层各取水样两次, 共 $20 \mathrm{~L}$, 混合后用 $25^{\#}$ 浮游生物网过滤, 收集于 $50 \mathrm{ml}$ 塑料瓶中, 用 $1 \mathrm{ml}$ 甲醛固定, 带回实验室鉴定浮游甲壳动物种类并计数 ${ }^{[11,20-21]}$. 


\section{3 数据分析}

数据分析处理使用 Excel 2007、SPSS 13.0 以及 Canoco 4.5 软件. 不同湖区浮游甲壳动物丰度以及环境 因子之间的差异采用方差法进行分析,丰度与环境理化因子的关系使用圥余分析 (RDA). 浮游甲壳动物优 势度的计算公式为 ${ }^{[22]}$ :

$$
Y=N_{i} f_{i} / N
$$

式中, $Y$ 表示物种优势度, $N_{i}$ 为第 $i$ 种的个体数, $N$ 为该样点所有个体总数, $f_{i}$ 为该种出现的频度. 当某一物种 $Y \geqslant 0.02$ 时, 可视为优势种类.

\section{2 结果与分析}

\section{1 水体理化指标}

采样期间水温范围为 $28.9 \sim 31.8^{\circ} \mathrm{C}$, 底层水温较表层稍低, 但差异不显著 $(P>0.05)$; 三个区域水温也 无显著差异 $(P>0.05)$. 全湖 $\mathrm{pH}$ 平均值为 7.92 , 范围为 $7.08 \sim 9.03$; 荷花区、湖岸区、敞水区的 $\mathrm{pH}$ 值逐渐变 高, 其中荷花区和湖岸区的 $\mathrm{pH}$ 值显著低于敞水区 $(P<0.05)$. 虽然荷花区的氮、磷浓度较高, 但其水体中叶 绿素 a 浓度却显著低于敞水区 $(P<0.05)$. 总悬浮质 $(\mathrm{TSS})$ 浓度在荷花区、湖岸区及敞水区中依次显著增高 $(P<0.05)($ 表 1$)$.

表 1 玄武湖不同区域理化参数平均值及范围

Tab. 1 Mean and range of physical-chemical parameters in different zones of Lake Xuanwu

\begin{tabular}{cccc}
\hline 参数 & 荷花区 & 湖岸区 & 敞水区 \\
\hline $\mathrm{TN} /(\mathrm{mg} / \mathrm{L})$ & $2.13(1.47 \sim 3.13)$ & $2.01(1.61 \sim 2.44)$ & $2.07(1.53 \sim 2.61)$ \\
$\mathrm{TDN} /(\mathrm{mg} / \mathrm{L})$ & $1.25(0.87 \sim 1.67)$ & $1.10(0.75 \sim 1.91)$ & $0.86(0.61 \sim 1.13)$ \\
$\mathrm{TP} /(\mathrm{mg} / \mathrm{L})$ & $0.25(0.19 \sim 0.41)$ & $0.24(0.21 \sim 0.29)$ & $0.27(0.21 \sim 0.34)$ \\
$\mathrm{TDP} /(\mathrm{mg} / \mathrm{L})$ & $0.10(0.04 \sim 0.28)$ & $0.078(0.03 \sim 0.18)$ & $0.084(0.04 \sim 0.25)$ \\
$\mathrm{TSS} /(\mathrm{mg} / \mathrm{L})$ & $15.47(2.33 \sim 32.50)$ & $20.85(10.67 \sim 30.50)$ & $27.95(19.00 \sim 45.00)$ \\
$\mathrm{Chl} . \mathrm{a} /(\mu \mathrm{g} / \mathrm{L})$ & $44.62(17.31 \sim 77.15)$ & $56.04(29.68 \sim 110.29)$ & $80.82(61.56 \sim 112.44)$ \\
$\mathrm{DO} /(\mathrm{mg} / \mathrm{L})$ & $5.04(1.90 \sim 8.89)$ & $6.49(3.02 \sim 9.05)$ & $8.02(6.59 \sim 9.61)$ \\
$\mathrm{pH}$ & $7.76(7.08 \sim 8.31)$ & $7.86(7.29 \sim 8.51)$ & $8.20(7.49 \sim 9.03)$ \\
\hline
\end{tabular}

\section{2 种类组成}

全湖共检出浮游甲壳动物 11 种,其中枝角类 8 种, 桡足类 3 种. 枝角类为模糊秀体溞、微型裸腹溞、尖额 溞、壳纹船卵溞、缺刺新秀体溞、短腹平直溞、盘肠溞以及棘体网纹溞; 桡足类为北碚中剑水蚤、台湾温剑水 蚤以及真剑水蚤 (表 2).

\section{3 丰度及优势种}

全湖浮游甲壳动物平均丰度为 4.4 ind. $/ \mathrm{L}$, 范围在 $0.5 \sim 15.9$ ind. $/ \mathrm{L}$ 之间; 枝角类平均丰度为 2.5 ind. $/ \mathrm{L}$, 占总丰度的 $56.7 \%$, 桡足类占 $16.2 \%$, 桡足类无节幼体占 $27.1 \%$. 枝角类优势种为模糊秀体溞、 微型裸腹溞、尖额溞及壳纹船卵溞,其丰度分别占枝角类总丰度的 $70.3 \% 、 15.0 \% 、 7.8 \%$ 和 $5.0 \%$; 桡足类 中, 北碚中剑水蚤和台湾温剑水蚤为优势种,两者丰度分别占桡足类总丰度的 $51.8 \%$ 和 $47.5 \%$.

\section{4 水平分布}

玄武湖浮游甲壳动物的水平分布表现为不均一性 (图 2). 枝角类在敞水区丰度最高, 平均丰度为 3.1 ind. $/ \mathrm{L}$, 其次是荷花区及湖岸区; 桡足类在荷花区种类最多, 其平均丰度为 $1.5 \mathrm{ind} . / \mathrm{L}$, 显著高于其他水 域 $(P<0.05)$; 无节幼体在荷花区的平均丰度也最高, 为 1.8 ind. $/ \mathrm{L}$ ( 图 3a). 纵观全湖荷花区, 枝角类优势种 为模糊秀体溞、微型裸腹溞、尖额溞和壳纹船卵溞,而位于东南湖东部的荷花区其枝角类种类最多,优势种 为尖额溞、壳纹船卵溞、微型裸腹溞和模糊秀体溞, 此外还存在缺刺新秀体溞、短腹平直溞、盘肠溞、棘体网 纹溞等种类. 湖岸区和敞水区的枝角类优势种是模糊秀体溞和微型裸腹溞, 且模糊秀体溞在敞水区的丰度 显著高于其它水域 $(P<0.05)$ (图 3b). 
表 2 玄武湖浮游甲壳动物不同种类丰度和出现率

Tab. 2 Abundance and frequencies of different species of crustacean planktons in Lake Xuanwu

\begin{tabular}{|c|c|c|c|c|}
\hline 物种 & 分布范围 & 出现率/\% & 平均丰度/(ind. /L) & 丰度范围 $/($ ind. $/ \mathrm{L})$ \\
\hline \multicolumn{5}{|l|}{ 枝角类 ( Cladocera) } \\
\hline 模糊秀体溞 (Diaphanosoma dubium) & 全湖 & 100.0 & 1.8 & $0.1 \sim 2.4$ \\
\hline 微型裸腹溞( Moina micrura) & 全湖 & 80.0 & 0.4 & $0 \sim 7.3$ \\
\hline 尖额溞( Alona sp. ) & 东南湖荷花区 & 7.5 & 0.2 & $0 \sim 6.0$ \\
\hline 壳纹船卵溞 (Scapholeberis kingi) & 全湖 & 25.0 & 0.1 & $0 \sim 3.3$ \\
\hline 缺刺新秀体溞( Neodiaphanosoma volzi) & 东南湖荷花区 & 5.0 & $<0.1$ & $0 \sim 1.2$ \\
\hline 短腹平直溞( Pleuroxus aduncus) & 东南湖荷花区 & 5.0 & $<0.1$ & $0 \sim 0.3$ \\
\hline 盘肠溞 ( Chydorus sp. ) & 东南湖荷花区 & 2.5 & $<0.1$ & $0 \sim 0.2$ \\
\hline 棘体网纹溞 (Ceriodaphnia setosa) & 东南湖荷花区 & 5.0 & $<0.1$ & $0 \sim 0.1$ \\
\hline \multicolumn{5}{|l|}{ 桡足类( Copepoda) } \\
\hline 北碚中剑水蚤( Mesocyclops pehpeiensis) & 全湖 & 85.0 & 0.4 & $0 \sim 5.9$ \\
\hline 台湾温剑水蚤 (Thermocyclops taihokuensis) & 全湖 & 80.0 & 0.3 & $0 \sim 3.6$ \\
\hline 真剑水蚤 (Eucyclops sp. ) & 东南湖荷花区 & 5.0 & $<0.1$ & $0 \sim 0.2$ \\
\hline 无节幼体 (Nauplii) & 全湖 & 95.0 & 1.2 & $0 \sim 6.8$ \\
\hline
\end{tabular}
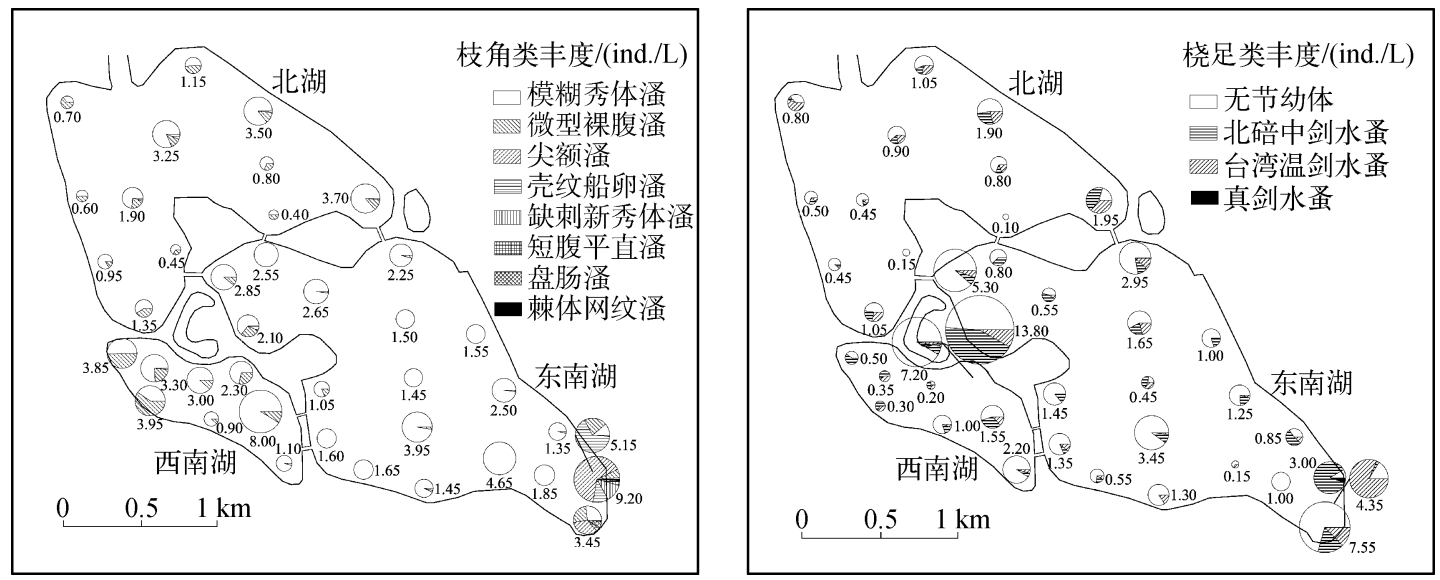

图 2 玄武湖浮游甲壳动物不同种类丰度所占比例

Fig. 2 Spatial distributions of abundances of different species of crustacean planktons in Lake Xuanwu

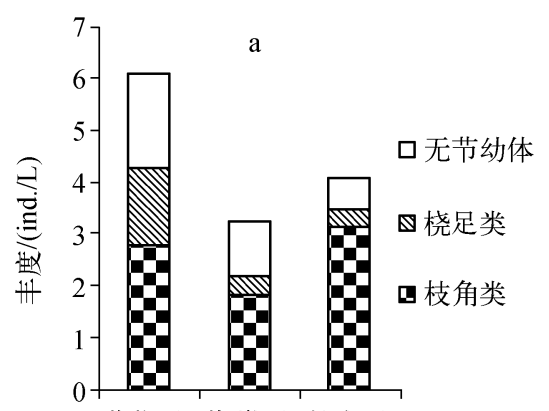

荷花区 湖岸区 敞水区

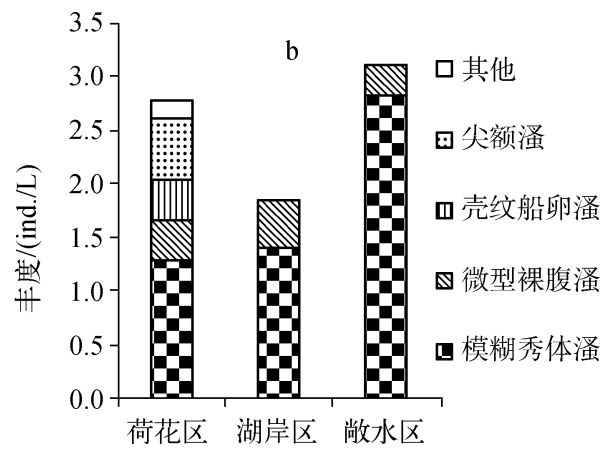

荷花区 湖岸区 敞水区

图 3 玄武湖 3 个区域不同浮游甲壳动物类群的丰度比较

Fig. 3 Average abundance of different crustacean planktons in three zones of Lake Xuanwu 


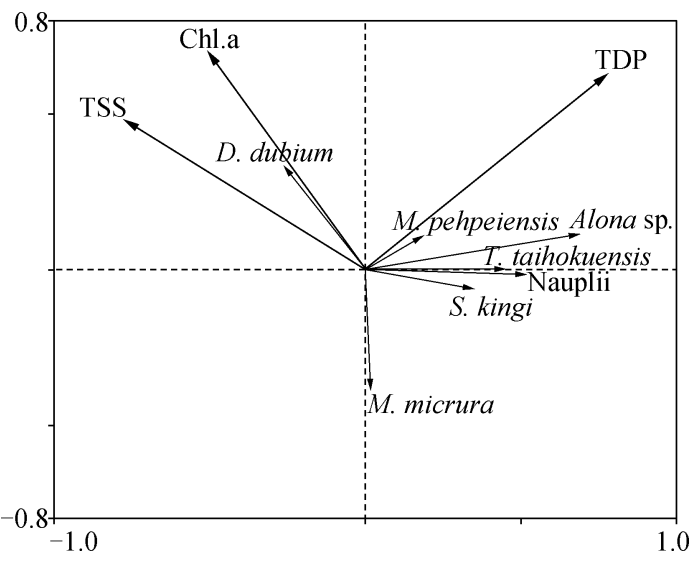

图 4 玄武湖浮游甲壳动物与环境关系的 RDA 排序图

Fig. 4 Biplot of the first two axes of the RDA for environmental factors associated with crustacean planktons in Lake Xuanwu

\section{5 浮游甲壳动物与环境因子的关系}

圥余分析表明, 与玄武湖浮游甲壳动物优势种 分布相关的首要环境因子为 TSS、Chl. a 和 $\operatorname{TDP}(P$ $<0.05$ ) (图 4 ). 其中, 与模糊秀体溞 (D. dubium) 呈显著正相关的环境因子为 Chl. a 和 TSS, 而微型 裸腹溞 $(M$. micrura $)$ 、壳纹船卵溞 $(S$. kingi $)$ 及无节 幼体 (Nauplii) 则与这两个环境因子呈负相关; 北碚 中剑水蚤 (M. pehpeiensis)、尖额溞 (Alona sp.) 以及 台湾温剑水蚤 (T. taihokuensis) 与 TDP 呈正相关.

\section{3 讨论}

\section{1 玄武湖浮游甲壳动物组成}

$1970 \mathrm{~s}-1980 \mathrm{~s}$, 玄武湖的优势枝角类为微型裸 腹溞和短尾秀体溞(Diaphanosoma brachyurum $)^{[18]}$, 本次调查表明,玄武湖敞水带的优势枝角类为微型 裸腹溞和模糊秀体溞. 由于短尾秀体溞在分布上属 于北方种,在亚热带区域没有此种的分布, 蒋䁓治 先生等所描述的短尾秀体溞应为模糊秀体溞 ${ }^{[1,21]}$, 因此近 $40 \mathrm{a}$ 中, 玄武湖优势枝角类没有发生变化. 结合前 期研究结果表明,玄武湖营养盐水平在 2006-2011 年间无较大变动, TN 浓度在 $1.5 \sim 3.0 \mathrm{mg} / \mathrm{L}$ 之间, TP 浓 度为 $0.05 \sim 0.27 \mathrm{mg} / \mathrm{L}^{[23]}$. 本研究结果与武汉东湖 ${ }^{[16]}$ 、杭州西湖 ${ }^{[24]}$ 、惠州西湖 ${ }^{[25]}$ 浮游甲壳动物的研究结果 对比得出, 枝角类中微型裸腹溞在四个城市湖泊中均为优势种, 桡足类中台湾温剑水蚤分布较广, 但由于各 个湖泊之间存在历史、营养盐、生境及气候的差异, 导致不同湖泊浮游甲壳动物优势种不完全一致,但整体 都是以小型化种类占优势 (表 3 ).

表 3 不同城市湖泊浮游甲壳动物优势种

Tab. 3 Dominant species of crustacean planktons in different urban lakes

\begin{tabular}{|c|c|c|c|c|}
\hline 城市湖泊 & $\mathrm{TN} /(\mathrm{mg} / \mathrm{L})$ & $\mathrm{TP} /(\mathrm{mg} / \mathrm{L})$ & 枝角类 & 桡足类 \\
\hline 南京玄武湖 & $1.5 \sim 3.0$ & $0.05 \sim 0.27$ & 模糊秀体溞、微型裸腹溞 & 北碚中剑水蚤、台湾温剑水蚤 \\
\hline 武汉东湖 & $2.0 \sim 5.4$ & $0.04 \sim 0.20$ & $\begin{array}{l}\text { 盔型透明溞、短尾秀体溞、微型裸腹溞、 } \\
\text { 透明薄皮溞 }\end{array}$ & $\begin{array}{l}\text { 近邻剑水蛋、广布中剑水蚤、 } \\
\text { 台湾温剑水蚤 }\end{array}$ \\
\hline 杭州西湖 & $1.9 \sim 2.5$ & $0.08 \sim 0.13$ & 长额象鼻溞、微型裸腹溞、长肢秀体溞 & 汤匙华哲水蚤、粗壮温剑水蚤 \\
\hline 惠州西湖 & $1.1 \sim 1.8$ & $0.08 \sim 0.13$ & 微型裸腹溞、角突网纹溞 & 温中剑水虫、台湾温剑水虫 \\
\hline
\end{tabular}

在玄武湖荷花区发现的缺刺新秀体溞为稀有枝角类,世界范围该物种的记录不多,就目前文献记载,该 物种只在热带及亚热带浅水湖泊及河流中出现 ${ }^{[26]}$. 在我国,除 1956 年蒋隻治先生在武汉东湖荷花区发现缺 刺新秀体溞 (Diaphanosoma aspinosum 为 Neodiaphanosoma volzi 的同物异名 ${ }^{[21,26]}$ ) 外 ${ }^{[27]}$, 尚有在长江河口和 香溪河存在的报道 ${ }^{[28-29]}$.

水体 $\mathrm{pH}$ 值可能是限制缺刺新秀体溞分布的因素之一,有研究表明其一般出现在微酸和中性环境中,如 武汉东湖, 此种即出现在微酸环境中 ${ }^{[27]}$, 泰国发现的该物种只生活在 $\mathrm{pH}$ 为 $6.4 \sim 7.2$ 的水体里 ${ }^{[12]}$. 本研究 中,缺刺新秀体溞丰度最高 $(1.2$ ind. $/ \mathrm{L})$ 的采样点其 $\mathrm{pH}$ 值也恰为全湖最低 $(\mathrm{pH}=7.08)$; 其次,该物种的游

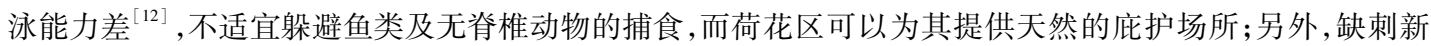
秀体溞也不适宜直接接触底层沉积物 ${ }^{[12]}$, 而荷花区湖底被大量荷叶残体覆盖, 一定程度上避免了该种与底 层沉积物的直接接触. 这些均可能是导致缺刺新秀体溞只出现在荷花区的原因.

相对于敞水区, 尖额溞更喜好生活在水生植被区 ${ }^{[30]}$, 本次调查中, 尖额溞只在玄武湖东南湖荷花区大量 出现. 除此之外, 短腹平直溞、盘肠溞、网纹溞及真剑水蚤由于游泳能力差 ${ }^{[11]}$, 不适于在敞水区大量繁殖, 因 
此在本次调查中仅在荷花区检出.

本次调查中存在于玄武湖东南湖荷花区的种类(如缺刺新秀体溞等)在其它荷花区并未发现,理化因子 分析表明,该荷花区的 TP 及 TDP 浓度均高于其它荷花区, pH 及 TSS 浓度则低于其它荷花区, 这可能是荷花 区面积不同导致的. 东南湖荷花区面积最大 (约 $40000 \mathrm{~m}^{2}$ ), 而其它荷花区面积较小 (均小于 $5000 \mathrm{~m}^{2}$ ). 相比 面积较小的荷花区, 面积较大的荷花区可能会更加有效地减小风浪扰动、改善沉积物特性、促进悬浮质沉 降, 从而使得其水体理化性质更加稳定,形成不同于敞水区、湖岸区及小型荷花区的特殊生境.

\section{2 水平分布与环境因子的关系}

水体氮磷营养盐浓度可能会对浮游甲壳动物丰度产生一定的影响, 一般认为浮游甲壳动物丰度与水体营 养盐水平呈正相关 ${ }^{[10]}$. 大型挺水植物在生长过程中会吸收底泥中的氮磷, 并将部分可溶性氮磷释放到水体中; 与此同时, 微生物在高温环境下也会加速分解其凋落物残体从而促进可溶性氮磷的释放 ${ }^{[31]}$. 本研究中, 荷花区 氮磷营养盐浓度及浮游甲壳动物丰度均略高于其他湖区, 同时冗余分析表明北碚中剑水蚤、尖额溞以及台湾 温剑水虫与 TDP 呈正相关. 可见氮磷营养盐浓度可能是影响玄武湖浮游甲壳动物丰度水平分布的因素之一.

鱼类对浮游甲壳动物的捕食也是影响其水平分布的重要因素 ${ }^{[1,6]} .2008$ 年夏季对玄武湖的鱼类调查表明， 敞水区的鱼类以食浮游生物的鲢、鳙为主, 其相对捕获量是荷花区的 9 倍 ${ }^{[9]}$. 所以在水生植被区, 浮游甲壳动 物白天被滤食性鱼类捕食的风险要小 ${ }^{[32]}$. 本研究中, 秀体溞游泳能力强, 且身体较透明, 易于逃避鱼类捕食 ${ }^{[33]}$. 同时, 由于鱼类主要通过视觉进行捕食, 而玄武湖敞水区 TSS 浓度(平均值为 $27.95 \mathrm{mg} / \mathrm{L}$ ) 显著高于湖岸区和荷花 区 $(P<0.05)$, 浑浊水质会干扰鱼类捕食 ${ }^{[34]}$, 却不影响秀体溞生活 ${ }^{[13]}$, 故模糊秀体溞在敞水区的丰度显著高于沿 岸区和荷花区 $(P<0.05)$. 而其余浮游甲壳动物在敞水区及湖岸区的丰度均低于有庇护效果的荷花区.

夏季湖岸区的无脊椎动物密度很高, 一些种类 (如水生昆虫幼体) 也会对浮游甲壳动物造成较大的捕食 压力 ${ }^{[3]}$. 在浅水湖泊中, 一旦发生湖岸区无脊椎动物对浮游动物捕食的负效应大于沉水植物对其庇护的正 效应的现象, 就会导致中尺寸 $(0.7 \sim 0.9 \mathrm{~mm})$ 枝角类 (如秀体溞属) 趋向于浑浊的敞水区 ${ }^{[35-36]}$, 从而有利于 游泳能力强的浮游甲壳动物在此环境中生长繁殖. 故推测, 该现象可能也在玄武湖发生, 使得模糊秀体溞大 量在敞水区生活.

作为浮游甲壳动物的食物, 浮游植物的密度也是影响其分布的重要因素 ${ }^{[4-5,37]}$. 叶绿素 $\mathrm{a}$ 浓度代表水体 中浮游植物的密度, 因而在一定程度上可以体现水体中浮游甲壳动物的食物密度. 在浅水湖泊中, 大型水生 植物通过与浮游植物竞争光照和营养盐从而抑制浮游植物的生长 ${ }^{[38]}$, 本研究发现, 尽管玄武湖不同水域间 营养盐并无明显差异, 但大型植物仍可通过竞争光照抑制浮游植物的生长, 因而使得荷花区叶绿素 a 浓度 显著低于敞水区 $(P<0.05)$. 然而由于玄武湖常年处于富营养状态, 使得夏季浮游植物在数量上以蓝藻占绝 对优势, 即便在 2005-2006 年对玄武湖进行蓝藻水华治理后, 蓝藻数量仍约占总浮游植物的 $70 \%{ }^{[39]}$. 而蓝 藻并不适合为浮游甲壳动物食用, 因此结合本研究表明, 相比敞水区, 荷花区更可能存在食物限制的现象. 而荷花区除模糊秀体溞外的大部分浮游甲壳动物丰度都要高于其他湖区, 推测在采样期间玄武湖中除易于 躲避鱼类捕食的模糊秀体溞外,其余浮游甲壳动物的水平分布并不受食物因素主导.

致谢: 感谢蔡永久博士、赵晨露、李柯、何虎同学在软件应用方面的帮助,感谢两位审稿人的修改意见!

\section{4 参考文献}

[ 1 ] Meerhoff M, Iglesias C, De Mello FT et al. Effects of habitat complexity on community structure and predator avoidance behaviour of littoral zooplankton in temperate versus subtropical shallow lakes. Freshwater Biology, 2007,52 ( 6) : 1009-1021.

[ 2 ] Jensen ES, Brucet, Meerhoff M et al. Community structure and diel migration of zooplankton in shallow brackish lakes: role of salinity and predators. Hydrobiologia, 2010, 646(1) : 215-229.

[ 3 ] Masson S, Pinel-Alloul B. Spatial distribution of zooplankton biomass size fractions in a big lake: abiotic and( or) biotic regulation? Canadian Journal of Zoology-Revue Canadienne De Zoologie, 1998, 76( 5 ) : 805-823.

[ 4 ] White MD. Horizontal distribution of pelagic zooplankton in relation to predation gradients. Ecography, 1998, 21 (1): 44-62.

[ 5 ] Levesque S, Beisner BE, Peres-Neto PR. Meso-scale distributions of lake zooplankton reveal spatially and temporally varying trophic cascades. Journal of Plankton Research, 2010, 32(10) : 1369-1384.

[ 6 ] Lauridsen T, Jeppesen E, Landkildehus F et al. Horizontal distribution of cladocerans in arctic Greenland lakes-impact 
of macrophytes and fish. Hydrobiologia, 2001, $442(1 / 2 / 3): 107-116$.

[ 7 ] Castro BB, Marques SM, Goncalves F. Habitat selection and diel distribution of the crustacean zooplankton from a shallow Mediterranean lake during the turbid and clear water phases. Freshwater Biology, 2007, 52 (3) : 421-433.

[ 8 ] Cazzanelli M, Warming TP, Christoffersen KS. Emergent and floating-leaved macrophytes as refuge for zooplankton in a eutrophic temperate lake without submerged vegetation. Hydrobiologia, 2008, 605(1) : 113-122.

[9] 张 镇, 陈非洲, 周万平. 玄武湖挺水植物区与敞水区浮游甲壳动物昼夜水平迁移初探. 长江流域资源与环境, 2009, 18(10) : 919-925.

[10 ] Pinto-Coelho R, Pinel-Alloul B, Méthot G et al. Crustacean zooplankton in lakes and reservoirs of temperate and tropical regions: variation with tropic status. Canadian Journal of Fisheries and Aquatic Sciences, 2005, 62(2) : 348-361.

[11] 蒋览治, 堵南山. 中国动物志 (节肢动物门-甲壳纲-淡水枝角类). 北京: 科学出版社, 1979 .

[12] Korovchinsky NM. Redescription of Diaphanosoma volzi Stingelin, 1905 (Crustacea: Daphniiformes: Sididae) with remarks on comparative morphology, biology and geographical distribution. Hydrobiologia, 1995, 315(3) : 189-201.

[13 ] Dejen E, Vijverberg J, Nagelkerke LAJ et al. Temporal and spatial distribution of microcrustacean zooplankton in relation to turbidity and other environmental factors in a large tropical lake( L. Tana, Ethiopia). Hydrobiologia, 2004, 513 (1/2/ 3 ) : 39-49.

[14] Dodson SI, Lillie RA, Will-Wolf S. Land use, water chemistry, aquatic vegetation, and zooplankton community structure of shallow lakes. Ecological Applications, 2005, 15(4) : 1191-1198.

[15] Van Egeren SJ, Dodson SI, Torke B et al. The relative significance of environmental and anthropogenic factors affecting zooplankton community structure in Southeast Wisconsin Till Plain lakes. Hydrobiologia, 2011, 668(1) : 137-146.

[16] 鲁 敏, 谢 平. 武汉东湖不同湖区浮游甲壳动物群落结构的比较. 海洋与湖沼, 2002, 33(2): 174-181.

[17] 陈光荣, 雷泽湘, 谭 镇等. 环境因子对广东城市湖泊后生浮游动物的影响. 水生态学杂志, 2010, 3(4): 28-32.

[18] 徐家铸, 苏翠荣, 赵 强等. 富营养化与玄武湖浮游动物群落的演变. 南京师大学报: 自然科学版, 1991,14 (1) : 63-67.

[19］金相灿，屠清瑛. 湖泊富营养化调查规范. 北京：中国环境科学出版社, 1990: 43-82.

[20] 沈嘉瑞. 中国动物志 (节肢动物门-甲壳纲-淡水桡足类). 北京: 科学出版社, 1979 .

[21] Korovchinsky NM. Sididae, Holopediidae. Guides to the identification of the microinvertebrates of the continental of the World, 3. Hague: SPB Academic Publishing, 1992.

[22] 徐兆礼, 王云龙, 陈亚篗等. 长江口最大浑浊带区浮游动物的生态研究. 中国水产科学, 1995, 2(1): 39-48.

[23] 王锦旗, 郑有飞, 王国祥. 菹草种群对湖泊水质空间分布的影响. 环境科学, 2011, 32(2): 416-422.

[24] 李共国, 吴芝瑛, 虞左明. 引水和疏浚工程支配下杭州西湖浮游动物的群落变化. 生态学报, 2006, 26 (10): 3508-3515.

[25] 陈光荣, 钟 萍, 张修峰等. 惠州西湖浮游动物及其与水质的关系. 湖泊科学, 2008, 20(3): 351-356.

[26] Paggi JC, Da Rocha CEF. Neodiaphanosoma a new genus of Sididae( Branchiopoda, Ctenopoda) ; with description of $N$ bergamini sp. n. and comments on N. volzi(Stingelin 1905). Hydrobiologia, 1999, 397: 5-19.

[27] 蒋篎治. 武昌的秀体掻. 水生生物学集刊, 1956,(2): 308-312.

[28] 郭沛涌, 沈焕庭, 刘阿成等. 长江河口浮游动物的种类组成、群落结构及多样性. 生态学报, 2003, 23 (5): 892-900.

[29] 薛俊增, 韩新芹, 蔡庆华等. 香溪河库湾枝角类的种类组成及垂直分布. 水生生物学报, 2006, 30(1)：120-122.

[30] Whiteside MC, Williams JB, White CP. Seasonal abundance and pattern of Chydorid, Caldocera in mud and vegetative habitats. Ecology, 1978, 59(6):1177-1188.

[31] 李文朝, 陈开宁, 吴庆龙等. 东太湖水生植物生物质腐烂分解实验. 湖泊科学, 2001, 13(4): 331-336.

[32] Timms RM, Moss B. Prevention of growth of potentially dense phytoplankton populations by zooplankton grazing in the presence of zooplanktivorous fish in a shallow wetland ecosystem. Limnology and Oceanography, 1984, 29(3) : $472-486$.

[33] Liu ZW. Changes in abundance of the icefish Neosalanx pseudotaihuensis Zhang( Salangidae) and the impact on the zooplankton community of Xujiahe Reservoir, central China. Hydrobiologia, 2001, 445(1/2/3) : 193-198.

[34] Kirk KL. Suspended clay reduces Daphnia feeding rate: behavioural mechanisms. Freshwater Biology, 1991, 25(2) : 357-366.

[35] Schou MO, Rishol C, Lauridsen T et al. Restoring lakes by using artificial plant beds : habitat selection of zooplankton in a clear and a turbid shallow lake. Freshwater Biology, 2009, 54(7) : 1520-1531.

[36] González-Sagrario MA, Balseiro E. The role of macroinvertebrates and fish in regulating the provision by macrophytes of refugia for zooplankton in a warm temperate shallow lake. Freshwater Biology, 2010, 55(10) : 2153-2166.

[37] Burks RL, Lodge DM, Jeppesen E et al. Diel horizontal migration of zooplankton: costs and benefits of inhabiting the littoral. Freshwater Biology, 2002, 47 (3) : 343-365.

[38] Scheffer M, Hosper SH, Meij Er ML et al. Alternative equilibria in shallow lakes. Trends in Ecology and Evolution, $1993,8(8): 275-279$.

[39] 梅卓华, 张哲海, 赵春霞等. 南京玄武湖蓝藻水华治理后水质和浮游植物的动态变化. 湖泊科学, 2010, 22 (1): $44-48$. 